\title{
Lancisi's Sign: Giant C-V waves with Severe Tricuspid Regurgitation in Isolated Tricuspid Valve Prolapse
}

\author{
Sena Sert ${ }^{1}$ and Özlem Yildirimtürk ${ }^{1}$ \\ ${ }^{1}$ Istanbul Dr Siyami Ersek Thoracic and Cardiovascular Surgery Training and Research \\ Hospital
}

July 30, 2021

\begin{abstract}
IIntroduction Isolated tricuspid valve prolapse (TVP) is a rare finding on transthoracic echocardiography. Right atrial enlargement or prominent " $\mathrm{v}$ " waves as a consequence of hemodynamic changes in severe tricuspid regurgitation (TR) are rarely seen with isolated TVP. Here is a case of isolated prolapse of anterior tricuspid leaflet presenting with giant C-V waves also known as Lancisi's sign. Case Report A 66-year-old male presented with increasing exercise limitation and leg edema in recent months and was complaining about the persistent pulsation at his neck and elevated jugular venous pulse with prominent systolic pulsation that represents giant C-V waves, also known as 'Lancisi's sign' consequence of severe TR due to isolated prolapse of the anterior leaflet.The patients' symptoms resolved completely after tricuspid valve replacement. Discussion TVP is best defined at parasternal short axis view with more than $2 \mathrm{~mm}$ atrial displacement (AD) of leaflet/leaflets. TVP can also be detected from four chamber view with more than $2 \mathrm{~mm} \mathrm{AD}$ or in right ventricular inflow view with more than $4 \mathrm{~mm} A D$. As a consequence of TVP, the physiological jugular venous waveform alters due to severe TR.During severe TR; retrograde blood flow through right atrium during ventricular systole restrains $\mathrm{x}$ descent and produces a fusion of $\mathrm{c}$ and $\mathrm{v}$ waves that appears as a large pulsation in physical examination called as 'Lancisi's sign' Conclusion 'Lancisi's sign' is defined as a large visible systolic neck pulsation as a consequence of the $\mathrm{c}-\mathrm{v}$ waves fusion by preventing $\mathrm{x}$ descent during severe TR.
\end{abstract}

Lancisi's Sign: Giant C-V waves with Severe Tricuspid Regurgitation in Isolated Tricuspid Valve Prolapse Introduction

Tricuspid valve prolapse (TVP) is diagnosed if one or more leaflets extend beyond the tricuspid annular plane into the right atrium in late systole. TVP was present in $0.3 \%$ of individuals and most commonly associated with concomitant mitral valve prolapse (1). Isolated TVP is a rare finding on transthoracic echocardiography. Right atrial enlargement or prominent " v" waves as a consequence of hemodynamic changes in severe tricuspid regurgitation (TR) are rarely seen with isolated TVP (2). Here is a case of isolated prolapse of anterior tricuspid leaflet presenting with giant $\mathrm{C}-\mathrm{V}$ waves also known as Lancisi's sign.

Case Report

A 66-year-old male presented with increasing exercise limitation and leg edema in recent months and was complaining about the persistent pulsation at his neck. On physical examination, elevated jugular venous pulse with prominent systolic pulsation that represents giant $\mathrm{C}-\mathrm{V}$ waves, also known as 'Lancisi's sign' (Video-1) has detected. Cardiac auscultation revealed a loud pulmonary component of the second heart sound, and a holosystolic murmur at the left lower sternal border that increased with inspiration. Peripheral pitting pedal edema, and ascites were also noted. ECG showed 67 beats per minute with atrial fibrillation and right bundle branch block. Two-dimensional echocardiography revealed the presence of severe TR with isolated prolapse of the anterior leaflet (Figure-1). Dilated right heart chambers with moderate to severe 
right ventricular systolic dysfunction have also observed. He underwent tricuspid valve replacement and the patients' symptoms resolved completely after surgery.

Discussion

TVP has been rarely found as an isolated finding and more frequently found concomitantly with mitral valve prolapse. TVP is best defined at parasternal short axis view with more than $2 \mathrm{~mm}$ atrial displacement (AD) of leaflet/leaflets. TVP can also be detected from four chamber view with more than $2 \mathrm{~mm} \mathrm{AD} \mathrm{or} \mathrm{in} \mathrm{right}$ ventricular inflow view with more than $4 \mathrm{~mm} \mathrm{AD} \mathrm{(1).} \mathrm{The} \mathrm{largest} \mathrm{database} \mathrm{of} \mathrm{TVP} \mathrm{from} \mathrm{a} \mathrm{single} \mathrm{center,}$ retrospective study TVP was found to be associated with increased severity of TR (1).

The physiological jugular venous waveform contains 3 peaks and 2 descents. It exhibits the pressure increase in the right atrium during isovolumetric ventricular contraction as the $\mathrm{c}$ wave. Afterwards atrial relaxation causes a decrease in the right atrial pressure during mid-systole as we can see the $\mathrm{x}$ descent. The $\mathrm{v}$ wave occurs as a result of atrial filling during late systole in healthy individuals. During severe TR; retrograde blood flow through right atrium during ventricular systole restrains $\mathrm{x}$ descent and produces a fusion of $\mathrm{c}$ and $\mathrm{v}$ waves that appears as a large pulsation in physical examination called as 'Lancisi's sign' (Video-1) (3-5).

Conclusion

'Lancisi's sign' is defined as a large visible systolic neck pulsation as a consequence of the c-v waves fusion by preventing $\mathrm{x}$ descent during severe TR.

\section{References}

1- Lorinsky MK, Belanger MJ, Shen C, Markson LJ, Delling FN, Manning WJ, Strom JB. Characteristics and Significance of Tricuspid Valve Prolapse in a Large Multidecade Echocardiographic Study. J Am Soc Echocardiogr. 2021 Jan;34(1):30-37. doi: 10.1016/j.echo.2020.09.003. Epub 2020 Oct 16. PMID: 33071045; PMCID: PMC7796941.

2- Brown AK, Anderson V. Two-dimensional echocardiography and the tricuspid valve. Leaflet definition and prolapse. Br Heart J . 1983;49(5):495-500. doi:10.1136/hrt.49.5.495

3-Mansoor AM, Mansoor SE. IMAGES IN CLINICAL MEDICINE. Lancisi's Sign. N Engl J Med. 2016 Jan 14;374(2):e2. doi: 10.1056/NEJMicm1502066. PMID: 26760104.

4- Senguttuvan NB, Karthikeyan G. Jugular venous C-V wave in severe tricuspid regurgitation. N Engl J Med 2012;2013:e5.

5-Vigo V, Lisi P, Galgano G, Lomonte C. Lancisi's sign and central venous catheter tip position: a case report. J Vasc Access. 2018 Jan;19(1):92-93. doi: 10.5301/jva.5000760. PMID: 28731490.

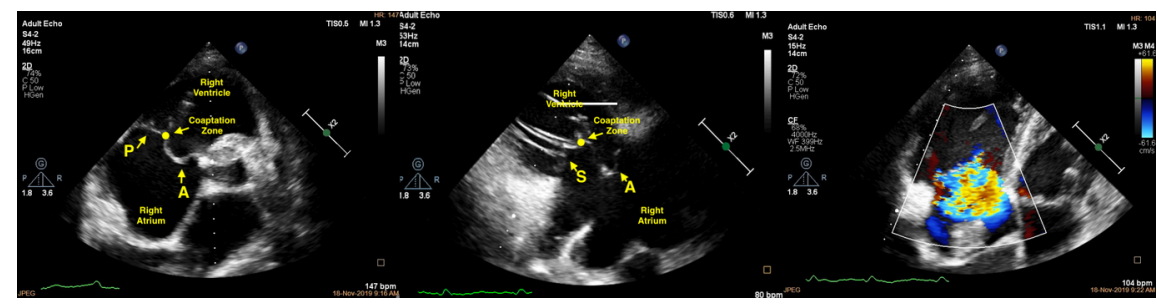

